Saudi Journal of Medical and Pharmaceutical Sciences

Abbreviated Key Title: Saudi J Med Pharm Sci

ISSN 2413-4929 (Print) |ISSN 2413-4910 (Online)

Scholars Middle East Publishers, Dubai, United Arab Emirates

Journal homepage: https://saudijournals.com

\title{
Primary Hyperoxaluria Diagnosed Late in Systemic Oxalosis Stage
}

Dr. Mounia Azizi ${ }^{*}$, Dr. Yassir Zajjari ${ }^{2}$, Dr. Abdelali Bahadi ${ }^{2}$, Dr. Hicham Rafik ${ }^{1}$, Dr. Ahmed Alayoud ${ }^{2}$, Dr. Driss Kabbaj $^{2}$

${ }^{1}$ Department of Nephrology-Dialysis, Military Hospital Mohammed V, Hay Ryad BP, 10100 Rabat Morocco

${ }^{2}$ Professor of Nephrology, Department of Nephrology-Dialysis, Military Hospital Mohammed V, Hay Ryad BP 10100 Rabat Morocco

DOI: $10.36348 /$ sjmps.2021.v07i02.001

| Received: 19.01.2021 | Accepted: 01.02.2021 | Published: 03.02.2021

*Corresponding author: Dr. Mounia Azizi

\section{Abstract}

Primary hyperoxaluria type 1 (PH1) is a rare disorder of glyoxylate metabolism, characterized by an excess of oxalate. Renal manifestations can range from occasional kidney stones, nephrolithiasis and recurrent nephrocalcinosis to endstage renal disease (ESRD) and systemic oxalosis. We report the case of a 32-year-old man, referred to our department for the management of bone pain. His parents were first degree cousins. The patient had a history of recurrent urolithiasis whose spectrophotometric study revealed an oxalocalcic lithiasis. He was on chronic hemodialysis program for the last 4 years with a presumed diagnosis of ESRD due to tubulo intersticiel nephropathy. He had diffuse bone pain for the last 8 months, more and more disabling and deforming. Clinical examination found bone signs such as thoracic deformity, bone pain on the palpation of the large joints and spine, waddling walk, hepatosplenomegaly and livedo reticularis. The assessment objectified multiple vertebral and sacroiliac osteolytic lesions and total cortical calcifications of both kidneys, normochromic anemia at $7.7 \mathrm{~g} / \mathrm{dl}$ with a ferritinemia at 1194, inflammatory syndrome with C reactive protein (CRP) at $50 \mathrm{mg} / \mathrm{l}$, normal calcemia at $90 \mathrm{mg} / 1$, hypoparathyroidism at $105 \mu \mathrm{g} / \mathrm{ml}$, hypothyroidism and bone biopsy revealed deposit of calcium oxalate crystals and crystal granulomas. In front of the consanguinity field, oxalocalcic repetitive lithiasis, nephrocalcinosis and the organic infiltration diffused by oxalate crystals, we concluded to systemic oxalosis. Pyridoxine hydrochloride treatment was combined to depleting dialysis while waiting for a potential liver and kidney donor.

Keywords: Oxalate, Nephrocalcinosis, Hemodialysis, Pyridoxine, liver, kidney, transplantation.

Copyright ( ) 2021 The Author(s): This is an open-access article distributed under the terms of the Creative Commons Attribution 4.0 International License (CC BY-NC 4.0) which permits unrestricted use, distribution, and reproduction in any medium for non-commercial use provided the original author and source are credited.

\section{INTRODUCTION}

Primary hyperoxaluria 1 (PH1) is an uncommon disease that affects principally kidney. PH1 is due to mutations in a gene called alanine-glyoxylate aminotransferase (AGXT). Inheritance is autosomal recessive It results from an excess of oxalate, substance which is ordinarily filtered through the kidneys. Renal manifestations can range from occasional kidney stones, nephrolithiasis and recurrent nephrocalcinosis to end-stage renal disease (ESRD) and systemic oxalosis. Treatment is based on minimising calcium deposit and preserving renal function. Thus an early diagnosis is essential so as to avoid reaching the end stage of renal failure $[1,2]$.

\section{Patient and Observation}

We report the case of a 32-year-old man that was referred to our departement for the management of bone pain. His parents were first degree cousins. The patient had a history of recurrent nephrolithiasis whose spectrophotometric study revealed an oxalocalcic lithiasis. He was on chronic hemodialysis program for the last 4 years with a presumed diagnosis of ESRD due to tubulo intersticiel nephropathy. He had diffuse bone pain for the last 8 months, more and more disabling and deforming, localized to 4 limbs, rachis and large joints and accentuating during hemodialysis sessions. Clinical examination found thoracic deformity, bone pain on the palpation of the large joints and spine, waddling walk and hepatosplenomegaly. Radiological assessment showed multiple vertebral and sacroiliac osteolytic lesions with total cortical calcifications of both kidneys in standard radiography. Bone scintigraphy revealed epiphyso-metaphyseal hyperfixation of the long bones as well as joints of the hands and feet related to the oxalate deposits. Laboratory results objectified normochromic anemia at $7.7 \mathrm{~g} \mathrm{/} \mathrm{dl}$ resistant to maximum dosage of erythropoeitine with a ferritinemia at 1194 and an inflammatory syndrome: CRP at 50, normal calcemia at $93 \mathrm{mg} / 1$ with hyperphosphoremia at $66 \mathrm{mg} / \mathrm{l}$ and hypoparathyroidism at $105 \mu \mathrm{g} / \mathrm{ml}$. Bone marrow biopsy showed calcium oxalate crystals and crystal granulomas. In front of the consanguinity field, 
oxalocalcic repetitive lithiasis, nephrocalcinosis and the diffuse organic infiltration by the oxalate crystals, we concluded to systemic oxalosis. Pyridoxine hydrochloride treatment was combined to depleting dialysis while waiting for a potential liver and kidney donor.

\section{DiscUSSION}

Primary hyperoxaluria is a rare disease with estimated prevalence and incidence rates of $0.8-$ 2.9/million population/year and $0.1-0.2 /$ million population/year, respectively [3]. Clinical presentation in our patient was similar to the literature data [4]. First signs of appeal were disabling bone pain aggravated by ultrafiltration, associated with a tumor syndrome made of hepatosplenomegaly. Bone lesions observed during oxalosis are related to the inflammatory reaction induced by oxalate crystals that can lead to bone deformations and fractures. They can be aggravated by hypoparathyroidism as our patient and several cases reported in the literature [5]. El Ghazal had published a similar case of which diagnosis was made late in the ESRD after 4 years of hemodialysis with systemic oxalosis [6].

The gold standard for the treatment of primary oxaluria is combined liver and kidney transplantation, although liver transplantation may be enough in those without involvement of the kidneys. Additionally, preemptive renal transplantation may be considered in selected cases with complete response to pyridoxine treatment. [7]

\section{CONCLUSION}

Our observation showed that diagnosis of primary oxaluria should be made as early as possible because combined liver- kidney transplantation can achieve long-term survival.

\section{REFERENCES}

1. Primary hyperoxaluria. Genetics Home Reference. December, 2015.

2. Coulter-Mackie, M. B., White, C. T., Hurley, R. M., Chew, B. H., \& Lange, D. (2014). Primary Hyperoxaluria Type 1. GeneReviews.

3. Hoppe, B., Beck, B. B., \& Milliner, D. S. (2009). The primary hyperoxalurias. Kidney international, 75(12), 1264-1271.

4. Tahar, G., Nourchène, K., Gharbi, Y., Wiem, K., Rachid, L. M., \& Jaouida, A. (2012). primary hyperoxaluria type 1 in tunisien children. Saudi J Kidney Dis Transpl, 23(2), 385-90.

5. Karadag, S., Gursu, M., Aydin, Z., Uzun, S., Dogan, O., Ozturk, S., \& Kazancioglu, R. (2011). Primary hyperoxaluria in an adult presenting with end- stage renal failure together with hypercalcemia and hypothyroidism. Hemodialysis International, 15(4), 573-576.

6. El Ghali, Z., Lahcen, Z. A., Fadili, W., Kaitouni, A. I., Hakkou, M., Hamdaoui, A., \& Laouad, I. (2014). Late diagnosis of a primary hyperoxaluria in terminal stage of chronic renal failure with severe hypoparathyroidism. The Pan African Medical Journal, 17, 297-297.

7. Hoppe, B., \& Leumann, E. (2004). Diagnostic and therapeutic strategies in hyperoxaluria: a plea for early intervention. Nephrology Dialysis Transplantation, 19(1), 39-42. 